\title{
Depuración de funcionarios diplomáticos durante la guerra civil
}

\author{
Marina Casanova Gómez
}

El inicio de la guerra civil dio lugar a la formación de una doble diplomacia que tuvo que restructurarse en función de las nuevas circunstancias y adoptó un sistema de depuraciones de funcionarios diplomáticos en ambos bandos para conseguir la absoluta fidelidad de los mismos.

Sin embargo, la confusa situación provocada por la guerra civil dificultó enormemente la tarea de reformar la Carrera Diplomática para adaptarla a la nueva situación creada, y uno y otro Gobierno fueron dictando numerosas disposiciones que eran rápidamente modificadas. Este carácter de provisionalidad constituyó la nota preponderante a lo largo de toda la contienda, lo que provocó, dentro del lógico desorden existente, una gran confusión entre los funcionarios diplomáticos, que explica en parte sus vacilaciones y reticencias a la hora de tener que definirse por uno $u$ otro bando.

El Gobierno republicano tuvo que enfrentarse rápidamente a la nueva situación, y el 22 de julio de 1936 promulgó un Decreto disponiendo el cese de todos los funcionarios que hubieran participado en el alzamiento del 18 de julio, o que fueran contrarios a los principios de la República. En aplicación de este Decreto, el Ministerio de Estado fue regulando el cese y separación de la Carrera Diplomática de los funcionarios pertenecientes a la misma o su paso a la situación de disponibles. Al mismo tiempo, y como consecuencia de las bajas producidas por los diplomáticos que presentaron su adhesión a la Junta de Defensa nacional, se realizaron numerosos cambios en las Representaciones de la República en el extranjero, hasta el punto que sólo durante el primer mes posterior al inicio de la 
guerra civil, el Ministerio de Estado llegó a cesar y separar del servicio a más de cien funcionarios diplomáticos ${ }^{1}$.

Sin embargo, exceptuando los casos más conocidos, la situación era demasiado confusa para determinar el comportamiento de cada uno de los diplomáticos objeto de una sanción sin el riesgo de caer en errores significativos. De este modo, se crearon situaciones un tanto anómalas, como el caso de Alfonso Fiscowich Gullón, Ministro Plenipotenciario de Segunda, encargado interinamente en la Embajada de España en Berlín desde el 31 de julio. Incorporado a su nuevo destino, cursó un telegrama al Ministerio de Estado dando cuenta de su reconocimiento por el Gobierno alemán y de sus conversaciones mantenidas con alto personal del Ministerio de Negocios Extranjero, en las que puso de relieve sus deseos de armonía y los lazos de amistad que le unían a los medios diplomáticos alemanes. Sin embargo, en la misma fecha cursó otro telegrama a la Junta de Defensa Nacional en contestación al enviado por el general Cabanellas, en el que manifestaba sus impresiones sobre la actitud del Gobierno alemán respecto a la Junta de Defensa Nacional. Cuando el Ministerio de Estado tuvo conocimiento de dicho telegrama decretó el cese de su cargo y su separación de la Carrera Diplomática.

Casos similares, aunque con soluciones diferentes se produjeron a menudo, funcionarios diplomáticos que fueron separados de la Carrera después de haber sido admitidos, o inversamente diplomáticos que fueron readmitidos después de haber sido inicialmente separados. Ante una situación tan confusa, el Ministerio de Estado tuvo que decretar el 21 de agosto de 1936 la disolución de la Carrera Diplomática, para constituir un nuevo escalafón integrado por los funcionarios que hubieran seguido prestando lealmente sus servicios a la República, y por aquellos que el Gobierno estimase oportuno designar libremente. No obstante, el Gobierno se reservó la facultad de revisar el nuevo escalafón para poder separar o cesar en sus funciones a algunos de esos diplomáticos.

En efecto, numerosos diplomáticos que en un primer momento permanecieron fieles a la República, se fueron progresivamente incorporando a la Junta de Defensa Nacional. A finales del mes de septiembre, setenta diplomáticos más habían sido separados de la Cariera recientemente constituída por la República el 21 de agosto.

Ante esta situación, el nuevo Presidente del Consejo de Ministros, Francisco Largo Caballero, dispuso la revisión y depuración de los funcio-

\footnotetext{
1 Véanse las Gaceta de Madrid del 22 y 28 de julio, 2, 4, 7, 8, 12 y 19 de agosto de 1936.
} 
narios públicos de forma unificada, y no como la que hasta el momento había sido realizada independientemente por cada Ministerio. El Decreto de 27 de septiembre de 1936 dispuso la suspensión de todos los derechos de los funcionarios, que en el plazo de un mes podrían solicitar su reingreso en los Ministerios correspondientes, en donde se determinaría la situación que les correspondiera en función del expediente formalizado.

La Junta de Defensa Nacional se encontró con un problema similar y tuvo que dictar una nueva normativa paralela a la existente en el Gobierno republicano. Sin embargo, durante los primeros meses, y hasta que no se estructuraron mínimamente sus órganos administrativos, la acción emprendida se limitó a la adopción de una serie de medidas que trataban de conseguir su reconocimiento internacional y el mayor número de adeptos por parte de los miembros de la Carrera Diplomática.

Por Orden de 30 de julio de 1936 se creó un Gabinete Diplomático con el fin de informar a la Junta de Defensa Nacional sobre asuntos relativos a su competencia, integrado por tres Secretarios de Primera, José Maria Bermejo Gómez, Antonio de la Cierva y Lewita y Vicente Taberna Latasa, seis Secretarios de Segunda, Gerardo Gasset y Neyra, Luis Roca de Togores y Pérez del Pulgar, Rafael Romero Ferrer, Antonio Villacieros Benito, Fernando Sebastián de Erice y O'Shea y Manuel Orbea Biardeu, y un Secretario de Tercera, Margarita Salaverría Galarraga. Teniendo en cuenta la rapidez en que fueron hechos sus nombramientos al inicio de la guerra civil está fuera de toda duda su fidelidad a la causa rebelde.

Con el fin de acelerar el proceso de reconocimiento de la Junta de Defensa Nacional por parte de las potencias extranjeras, el Presidente de la misma, general Cabanellas, envió el 24 de julio comunicaciones telegráficas a los diferentes Gobiernos extranjeros instándoles a mantener relaciones con el nuevo régimen constituído. Pero al inicio de la contienda la respuesta de la mayoría de los Gobiernos, incluído el alemán, fue negativa, y manifestaron que sólo mantendrían relaciones con el Gobierno republicano cerca del cual tenían acreditadas sus Representaciones.

Al estructurarse los Organos de Gobierno por la Ley de 1 de octubre de 1936, se creó una Secretaría de Relaciones Exteriores, encargada de dictar sanciones y separar definitivamente del servicio activo a aquellos funcionarios diplomáticos cuya postura, tanto anterior como posterior al alzamiento, hubiese sido contraria a éste. El cargo de Secretario de Relaciones Exteriores fue atribuido a Francisco de Asís Serrat y Bonastre que había sido Ministro Plenipotenciario de Primera con destino en Viena durante la Dictadura de Primo de Rivera, Embajador en la Habana, en Washington y Ministro en Varsovia durante la li República. 
Después del reconocimiento del Gobierno de Burgos por parte de Alemania e Italia (18 de noviembre de 1936), la Secretaría de Relaciones Exteriores decretó los primeros nombramientos oficiales de funcionarios diplomáticos en las Embajadas de Roma y Berlín y en los Consulados de Génova, Hamburgo, Franckfort, Munich y Trieste?

Por otro lado, no hay que olvidar que, junto a las representaciones oficiales ante los Gobiernos de Alemania e Italia, el Gobierno de Burgos estuvo representado de hecho, aunque no oficialmente, ante la mayoría de los Gobiernos extranjeros por medio de los llamados Agentes Oficiosos.

Sin embargo, la organización de la Carrera Diplomática sólo se inició mediante el Decreto-Ley de 11 de enero de 1937 que anunciaba la sustitución del escalafón del personal diplomático en vigor por uno nuevo, formado exclusivamente por aquellos funcionarios que hubiesen demostrado leal adhesión a la "causa de España", y serían dados de baja los que hubiesen permanecido leales al "Gobierno Rojo de Madrid" (sic). Se trataba de una decisión similar a la adoptada por el Gobierno republicano, y su elaboración tropezaría con las mismas dificultades, debido a los trámites legales para su realización, y a la lejanía de muchos funcionarios residentes en el extranjero.

En un primer momento se realizó una lista de funcionarios diplomáticos, que por su comprobada adhesión a la causa franquista fueron considerados acreedores a seguir representando al nuevo Gobierno ${ }^{3}$, mientras que los restantes diplomáticos deberían manifestar su deseo de continuar perteneciendo a la Carrera Diplomática. Estas peticiones de ingreso serían examinadas por una Comisión Depuradora constituída a tal efecto el 29 de enero de 1937. Integrada por funcionarios diplomáticos cuya fidelidad a la causa franquista quedaba fuera de toda duda, fue nombrado Presidente de la misma Miguel Espinós y Bosch, Ministro Plenipotenciario de Segunda, y como vocales los Secretarios de Primera Germán Baralbar Usandizaga, José del Castaño y Cardona, Francisco Javier Meruendano Fermoso y Gonzalo Sebastián de Erice y O'Shea que actuó como secretario.

Sin embargo, en la práctica, la elaboración del nuevo escalafón no fue tarea fácil. La provisionalidad que caracterizó a los organismos del Gobierno de Burgos a lo largo del año 1937, afectó muy especialmente a

2 Véase el Boletín Oficial del Gobierno de Burgos del 28 de diciembre de 1936.

3 Relación de diplomáticos declarados admitidos. Boletín Oficial del Gobierno de Burgos del 13 de enero de 1937. 
la Secretaría de Relaciones Exteriores. El normal desarrollo y aplicación de los Decretos realizados para la depuración del personal diplomático se vieron a menudo alterados. Los límites de tiempo establecidos para optar al reingreso o para la clasificación de los expedientes fueron insuficientes y las listas realizadas fueron repetidamente modificadas por la inclusión de funcionarios que, pese a no haber sido objeto de expediente, merecieron a juicio de la Comisión Depuradora ser separados de la Carrera Diplomática, o por el contrario, casos de diplomáticos separados del Cuerpo que con posterioridad fueron incluídos en las listas de admitidos.

Al iniciarse el año 1938 se disolvió la Junta Técnica y los organismos anejos y se creó el primer Gobierno Nacional. Los servicios centrales fueron reorganizados en Departamentos Ministeriales al frente de los cuales se nombró un ministro asistido de un subsecretario. El primer ministro de Asuntos Exteriores de Franco fue Francisco Gómez-Jordana y Sousa, conde de Jordana, militar que había sido miembro del Directorio del general Primo de Rivera, Alto Comisario en Marruecos entre 1928 y 1931 y Presidente de la Junta Técnica del Estado entre el 3 de junio de 1937 y su disolución de enero de 1938.

Ante los numerosos recursos entablados en la Secretaria de Relaciones Exteriores, fue necesario dotar a la Comisión Depuradora de un Tribunal con carácter permanente y con mayores garantías procesales para llevar a cabo la depuración de funcionarios diplomáticos, aunque dada la falta de elementos de prueba, dicho Tribunal tuvo carácter provisional. Constituido por el Decreto-Ley de 21 de enero de 1938, el Tribunal Seleccionador del personal del Cuerpo Diplomático y Consular tuvo como objetivo la revisión de los fallos emitidos por la Comisión Depuradora y el estudio de las peticiones de reingreso de los funcionarios formulados con posterioridad a la actuación de la Comisión Depuradora. Actuó como Presidente Alejandro Padilla y Bell, Embajador de España y como vocales Vicente González Arnao, Ministro Plenipotenciario de Primera, Juan Teixidor y Sánchez, Ministro Plenipotenciario de Tercera, y los Secretarios de Primera, José del Castaño y Cardona y Tomás Suñer y Ferrer.

Curiosamente la composición de los miembros de este Tribunal fue sometida a otro Tribunal que, según el Decreto de 5 de abril de 1938, debería "ofrecer las máximas garantías por la absoluta independencia e imparcialidad de sus componentes". Actuó como presidente el ministro de Asuntos Exteriores, y como vocales el subsecretario del Ministerio, Eugenio Espinosa de los Monteros y Bermejillo, el Embajador de España Bernardo Almeida Herreros y el Secretario de Primera Luis Alvarez de Estrada que actuó como secretario del Tribunal. 
Al estar presidido por el propio ministro de Asuntos Exteriores e integrado entre otras personalidades por el subsecretario de dicho Departamento, no cabe duda que esa "absoluta independencia e imparcialidad" sólo podía significar su capacidad para proceder a un riguroso control de la ideologia política de los miembros del Tribunal Seleccionador, quienes a su vez deberían juzgar el comportamiento de los funcionarios diplomáticos.

Efectivamente, para los dirigentes franquistas existia la duda de la fidelidad de un sector de diplomáticos, y en consecuencia trataron de organizar un Cuerpo Diplomático verdaderamente adicto a los ideales del "Movimiento", por lo que los requisitos exigidos para la admisión de los diplomáticos se fueron volviendo cada vez más exigentes.

Por ello, el Tribunal Seleccionador dictó nuevas normas para las solicitudes de ingreso en el escalafón diplomático en las que los interesados deberían especificar la situación y el lugar donde se encontraban el 18 de julio de 1936, fecha en la que presentaron su dimisión, si habian prestado su adhesión al Movimiento o por el contrario al Gobierno de la República, y,finalmente, los servicios prestados desde el 18 de julio cuando se produjo la renuncia a su cargo.

Si en la primera reorganización del Cuerpo Diplomático, según el Decreto-Ley de 11 de enero de 1937, sólo se exigió a los funcionarios admitidos su leal adhesión a la causa franquista, mediante el Decreto-Ley de 21 de enero de 1938 se les exigió además, no haber prestado en el pasado ningún servicio al Gobierno republicano, haber enviado el telegrama de adhesión a la Junta de Defensa Nacional, y no haber prestado servicio alguno al Gobierno republicano con posterioridad al 18 de julio.

Del mismo modo, serian declarados admitidos aquellos funcionarios que no recibieron el telegrama solicitando su adhesión y permanecieron en sus puestos un tiempo prudencial que sería determinado por el Tribunal Seleccionador, teniendo en cuenta la distancia y los medios de comunicación. Igualmente serían declarados admitidos los funcionarios que sin haber realizado servicios perjudiciales a la causa franquista, permanecieron en sus puestos por orden de las autoridades del momento, hecho que obviamente tenía que ser justificado.

Serían declarados disponibles aquellos diplomáticos que permanecieron en sus puestos después del 18 de julio, pero que de alguna manera manifestaron sus simpatias a la causa franquista. 
Serian declarados jubilados aquellos funcionarios que no presentaron su adhesión al Movimiento y permanecieron en sus puestos, siempre y cuando no hubieren realizado servicios perjudiciales a la causa franquista.

Por último, los diplomáticos no incluidos en ninguna de las categorías mencionadas serían considerados separados del servicio.

El Tribunal Seleccionador consideró suficiente establecer un plazo de 60 días para la resolución de los expedientes, plazo que fue sucesivamente ampliado, debido a la lejanía, al aumento de requisitos para ser declarado admitido y a las enormes dificultades legales con que tropezó el Tribunal Seleccionador. En este sentido, de conformidad con la Orden de 26 de marzo de 1938 se ampliaron de modo más preciso y concreto los términos de la declaración jurada que exigía a los diplomáticos que justificasen su fidelidad, no sólo después del 18 de julio, sino también a partir de la convocatoria de las elecciones de 16 de febrero de 1936. Asimismo, se consideró motivo de depuración el hecho de que los diplomáticos hubieran estado afiliados a alguno de los partidos integrados en el "Frente Popular», e incluso el haber cotizado voluntaria o coactivamente en favor de una larga lista integrada por 18 organizaciones y partidos.

El procedimiento seguido para la investigación de los funcionarios diplomáticos se desarrolló mediante el requerimiento por parte del subsecretario de Asuntos Exteriores a la Jefatura del Servicio Nacional de Seguridad de los informes que obraban en dicho Centro del personal del Cuerpo Diplomático y Consular del antiguo Ministerio de Estado. A continuación, recibidos los informes se enviaban al presidente del Tribunal Seleccionador, quien junto con los demás miembros del Tribunal decidirian el «pronunciado" correspondiente.

Un supuesto interesante consistía en el hecho de haber pertenecido a Logias masónicas españolas o extranjeras, mencionado expresamente en la citada Orden de 26 de marzo, que especificaba la obligación de los diplomáticos de declarar si habian pertenecido a la Masonería. En este caso, además de los informes procedentes de la Jefatura del Servicio Nacional de Seguridad, se añadía otro informe más detallado procedente de la Delegación Nacional de Servicios Especiales de la Secretaría Particular del Generalísimo, donde se encontraban los Archivos de antecedentes masónicos. Desde Salamanca la información era enviada al subsecretario del Miristerio de Asuntos Exteriores, quien a su vez la remitía al Tribunal Seleccionador.

Tal fue el caso del Secretario de Tercera destinado en el Consulado de Orán, Oscar Peña y Camús, que había sido separado del servicio por 
el Gobierno de la República el 19 de agosto de 1936. En el expediente abierto a dicho funcionario por el Tribunal Seleccionador existe un despacho reservado de fecha 9 de octubre de 1936, firmado por el ministro de España en Tánger, Juan Peche, que afirmaba que el Sr. Peña Camús se adherió al Movimiento Nacional, siéndole encomendados algunos servicios en Casablanca, pero que con posterioridad desapareció, supone el Sr. Peche, por miedo, pues al parecer era «masón" ${ }^{4}$. En el mismo expediente se incluyó un informe detallado sobre su actuación a partir del 18 de julio de 1936 procedente de la Delegación Nacional de Servicios Especiales de la Secretaría Particular del Generalísimo, que relataba cómo el Cónsul de España en Arcila, Sr. García Llera, recibió el 18 de julio la visita del Sr. Peña Camús quien ofreció sus servicios a las fuerzas sublevadas acompañando a elementos de Falange Española.

Sin embargo, pese a la fidelidad demostrada por el Sr. Peña Camús al Movimiento Nacional, elementos de Falange comenzaron a tratarle con cierta frialdad al tener conocimiento de sus antecedentes masónicos, hecho que el propio cónsul de Arcila conocía. Ante tal situación, y pese a que el Sr. Peña Camús había declarado su renuncia a la Logia masónica a la que pertenecía, tuvo que trasladarse a Bruselas. El Tribunal Seleccionadrod, a la vista de los informes recibidos, incluyó al Sr. Peña Camús en la lista de funcionarios diplomáticos disponibles ${ }^{5}$.

Del mismo modo procedió con el Secretario de Tercera, Vicente Aparicio Ollero, quien se encontraba en el Consulado de Estambul al iniciarse la guerra civil, y fue separado del servicio activo por el Gobierno de la República el 19 de agosto de 1936. Cuando el Tribunal Seleccionador estudió su caso, pese a su pertenencia a la Logia "Conde de Aranda" con el grado 2, fue incluido en la lista de disponibles.

Sin embargo, otros cinco diplomáticos incluidos en la lista de personal diplomático y consular pertenecientes a la masonería, no obtuvieron la misma sanción dado que el Tribunal Seleccionador tuvo también en cuenta otros agravantes, generalmente de índole política.

Así entendió el Tribunai en el caso de Emilio Zapico Zarraluqui, Ministro Plenipotenciario de Primera, perteneciente a la Logia «Constitucionalis-

\footnotetext{
${ }^{4}$ Informe del ministro de España en Tánger a la Secretaria de Relaciones Exteriores sobre la actitud del personal diplomático en las dos zonas de Marruecos y Tánger. AMAE. Fondo Navasques. Depuración de funcionarios diplomáticos. 9 de octubre de 1936.

5 Informe de la Delegación Nacional de Servicios Especiales de la Secretaria Particular del Generalisimo. Salamanca, 16 de abril de 1938. AMAE. Fondo Navasques. Depuración de funcionarios diplomáticos.
} 
ta 16». Al iniciarse la guerra se encontraba en México desempeñando el cargo de Cónsul general, país en el que continuó trabajando al servicio de la República. Por este motivo fue dado de baja en el escalafón del Cuerpo Diplomático en agosto de 1938.

Lo mismo ocurrió con Rafael Suárez Rivas, Secretario de Tercera perteneciente a la Logia "Conde de Aranda" con el grado 3. El Tribunal Seleccionador encontró en su expediente sobrados motivos para separarle del Cuerpo. Antes de iniciarse el alzamiento ya había manifestado su militancia política a favor de la República. En 1935 fue elegido vocal titular de la "Liga española de los Derechos del Hombre». Al estallar la guerra se encontraba en Madrid donde, según la Jefatura del Servicio Nacional de Seguridad, trató de tomar represalias con las familias de los funcionarios diplomáticos que habían dimitido de sus cargos, vestido de miliciano y armado.

Igualmente Clemente Cerdeira, procedente del Cuerpo de Intérpretes, afiliado a la Logia española de "Morayta» trató de levantar las kabilias contra el Generalísmo Franco el 18 de julio de 1936 cuando estaba al frente del Consulado del Gobierno republicano en Tánger. Considerado como elemento marxista fue dado de baja en el escalafón en agosto de 1936.

Salvador Téllez Molina, Secretario de Tercera, perteneciente a la Logia de Gibraltar. El Tribunal Seleccionador consideró que, no sólo había permanecido fiel a la República desde su puesto en Valparaíso, sino que además realizó actos tendentes a obstaculizar la actuación de los agentes oficiosos en Chile, quienes se proponian conseguir recursos y reclutar adeptos para la causa franquista.

Finalmente el caso de Rafael Fernández Ramos, Secretario de Primera y perteneciente a la Logia Oriente. Fue Cónsul de España en Burdeos representando al Gobierno de Valencia. Sin embargo, pese a estar considerado muy izquierdista y haber realizado numerosos trabajos para el Gobierno republicano, fue destituido del cargo el 19 de junio de 1937 acusado de haber realizado un desfalco en los negocios de exportación de naranjas del Gobierno republicano. El Tribunal Seleccionador le dio de baja en agosto de 1938 .

De los 438 diplomáticos incluidos en la relación de personal diplomático y consular, sólo siete tenían abierto expediente en la Delegación $\mathrm{Na}$ cional de Servicios Especiales. De estos siete diplomáticos, tres pertenecían a Logias del Norte de Africa; dos a Logias de Madrid; uno a la Logia de Gibraltar y uno a la Logia de México. De ello puede deducirse la escasa 
participación de los funcionarios diplomáticos en las actividades de la masonería.

Pese a la conocida y notoria fobia que el general Franco experimentó hacia la masonería, y que le llevaría a dictar la Ley de Represión de la Masonería y el Comunismo el 1 de mayo de 1940, los "pronunciados" del Tribunal Seleccionador ponen de manifiesto que la pertenencia a la masonería no fue motivo exclusivo para la separación de funcionarios de la Carrera Diplomática, siempre y cuando hubiesen demostrado su adhesión a la causa franquista. En tales casos las resoluciones del Tribunal tuvieron solamente carácter de sanción temporal. Por el contrario, aquellos diplomáticos que, además de su afiliación a Logias masónicas, permanecieron fieles al Gobierno de la República, fueron separados de la Carrera Diplomática de forma definitiva.

A pesar de que todavia quedaron pendientes de revisión algunos expedientes, antes de terminar el año 1938 se habían hecho públicas las listas de los funcionarios diplomáticos sobre los cuales habia recaído un «pronunciado» aparejado de sanción, ya fuesen «separados», «disponibles» 0 «jubilados» ${ }^{6}$.

Sesenta y dos diplomáticos fueron «separados" de la Carrera; dieciocho «jubilados» y treinta y seis en situación de "disponibles». Si se tiene en cuenta que el número total de diplomáticos ascendía a 438 al iniciarse la guerra civil, puede deducirse que la mayoría recibieron el "pronunciado" de "admitidos", aunque tal hecho debe ser convenientemente matizado, para no caeer en fáciles conclusiones que puedan inducir a error.

En la primera relación de diplomáticos «admitidos», publicada el 13 de enero de 1937, se computan 146, por lo que en una primera aproximación no sería ilógico deducir que su ideología política era de derechas y que tomaron su decisión de apoyar a Franco mucho antes de que pudiera preverse el final de la contienda. Sin embargo, dos de ellos, Vicente Taberna Latasa y Manuel Orbea figuran con antecedentes republicanos, aunque al tener conocimiento del alzamiento se pusieron a las órdenes del Gobierno de Franco.

Los diplomáticos que fueron declarados «admitidos» entre agosto y diciembre de 1938 representan un grupo que no tomó una decisión inmediata el 18 de julio y solamente se vieron obligados a definirse políticamen-

\footnotetext{
6 Véanse las listas de funcionarios diplomáticos declarados «jubilados» y «separados" por el Tribunal Seleccionador. Boletin Oficial de 27 de agosto de 1938.
} 
te cuando en septiembre de 1936 llegó al poder Largo Caballero. De ello puede deducirse que su toma de posición no lo fue tanto en favor de Franco como en contra de la ideología socialista del nuevo Gobierno, lo que no parece sorprendente si se tiene en cuenta el marcardo carácter conservador que siempre había definido a la Carrera Diplomática.

Entre estos diplomáticos podemos clasificar a un primer grupo integrado por 87 funcionarios que fueron declarados "admitidos" por el Tribunal Seleccionador al considerarles afectos al Movimiento Nacional sin más especificaciones.

Existe un segundo grupo formado por diplomáticos que habían pertenecido a algún partido político con anterioridad a la II República, o con posterioridad, a partidos de tendencias derechistas. Entre ellos aparecen tres que pertenecieron a las Juventudes Mauristas; uno a la Juventud del Partido Liberal Conservador; uno al Partido Conservador; uno al Somatén creado por el General Primo de Rivera; uno a la CEDA; uno a Acción Popular; uno al Partido Carlista; uno al Requeté; uno a La Comunión Tradicionalista de Salamanca; dos a Renovación Española y cinco a Falange Española. De ello puede deducirse que la militancia política de los funcionarios diplomáticos en partidos de ideología derechista no fue numerosa.

Un tercer grupo está integrado por aquellos diplomáticos que actuaron como agentes oficiosos en aquellos países que todavía en 1938 no habian reconocido oficialmente el Gobierno de Franco; Rumania, Argentina, Panamá, Perú, Brasil, Estados Unidos, Tánger, Reino Unido, Cuba, Estonia, Austria, Finlandia, Francia, Grecia, Checoslovaquia, China, Bélgica, Portugal y México (en este país los dos agentes oficiosos fueron expulsados por el Gobierno mexicano).

Finalmente, un cuarto grupo formado por aquellos diplomáticos cuya actuación se encuentra fuera de toda clasificación, y que a veces parece contraria a la causa franquista, no obstante haber sido declarados «admitidos». Entre ellos se incluyen varios diplomáticos que se encontraban en Madrid al producirse el alzamiento, los cuales ante las detenciones realizadas por elementos republicanos, optaron por refugiarse en las Legaciones extranjeras, hecho que motivó numerosos problemas de orden político y humano. Los dirigentes republicanos trataron dentro de un límite, de proteger a determinadas personas significadas por su ideología derechista, y en contrapartida, de obtener la garantía de que los refugiados liberados no volverian a tomar las armas contra la República. Sin embargo, numerosos diplomáticos que se refugiaron en las Legaciones extranjeras en Madrid, al ser liberados regresaban a la España franquista presentándose a sus superiores en Salamanca. Algunos lo hicieron por motivos ideológicos; 
otros al conocer el menosprecio que las autoridades de Franco experimentaban por los funcionarios que no presentaron su adhesión al Movimiento desde el inicio del alzamiento ${ }^{7}$.

Dentro de este grupo incalificable figuran tres diplomáticos que fueron tachados de acomodaticios, arribistas y de dudosa conducta moral, constando en el expediente de uno de ellos, pese a tener inmejorables referencias, una nota desfavorable por hacerse acompañar de una mujer que no era su legítima esposa. Un diplomático había sido declarado disponible con anterioridad al 18 de julio de 1936 por el Gobierno de Azaña, «harto de sus pasteleos" (sic). Un diplomático que habia hecho alardes de ideas izquierdistas y de tener gran amistad con Salvador de Madariaga tuvo que alistarse en una bandera de Falange para rehabilitarse ante el Gobierno de Franco. Fue similar el caso de un diplomático que con anterioridad al 18 de julio de 1936, había manifestado sus ideas izquierdistas y sus creencias ateas, habiendo declarado que su mayor aspiración era ser nombrado primer embajador cerca del Gobierno de los Soviets. Después del 18 de julio renunció a su cargo ante el Gobierno republicano, y antes de llegar a España, estuvo molestando a súbditos españoles, obligándoles a que le entregasen dinero y joyas para el Gobierno de Franco a fin de hacer méritos. Varios diplomáticos se significaron por su amistad con personalidades del Gobierno republicano, tales como Azaña y Casares Quiroga.

A la vista de lo anteriormente expuesto se puede deducir que el grupo de "admitidos" ${ }^{8}$, salvo algunas excepciones, presenta una gran homogeneidad por lo que se refiere a su comportamiento político. En su mayoría no estuvieron afiliados a ningún partido, aunque demostraron sus simpatías por los grupos derechistas. Su comportamiento personal fue considerado satisfactorio. Al producirse el alzamiento apoyaron a las fuerzas rebeldes, hecho que el Tribunal Seleccionador valoró por encima de conductas, a veces no demasiado ortodoxas.

Los diplomáticos que permanecieron en sus puestos después del 18 de julio de 1936, pero que de alguna manera manifestaron sus simpatías a la causa franquista fueron declarados «disponibles», sufriendo la sanción de pérdida de puestos en el escalafón de su categoría correspondiente. Este grupo representa el 8,22 por 100 del personal diplomático y guarda una gran homogeneidad por lo que se refiere a su actuación después del

\footnotetext{
7 Véanse los informes del Ministerio de Orden Público de Faustino Armijo, Fernando Canthal, Juan Manuel Cano, Juan Felipe de Ranero, Angel Silvela, Luis de Silva, José Aragón y Carrillo de Albornoz. AMAE. Fondo Navasques. Depuración de funcionarios diplomáticos.

${ }^{8}$ Véanse los informes del Ministerio de Orden Público sobre los diplomáticos declarados "admitidos". AMAE. Fondo Navasques. Depuración de funcionarios diplomáticos.
} 
del 18 de julio de 1936, aunque con algunas excepciones. En su mayoría presentaron su adhesión al Gobierno de Burgos a lo largo del mes de septiembre de 1936, fer' $a$ que coincide con el momento en que fueron dados de baja en el Cuerpu Diplomático por el Gobierno de la República. Inmediatamente se convirtieron en agentes oficiosos de Franco en los países en los que se encontraban destinados ${ }^{9}$.

Dos diplomáticos fueron declarados "disponibles" a pesar de sus antecedentes masónicos. El diplomático y escritor Edgar Neville fue declarado igualmente "disponible» a pesar de los informes contradictorios del Ministerio de Orden Público. Los únicos cargos que pudieron imputársele fueron de carácter ideológico y personal. Así, por ejemplo, su absentismo laboral cuando desempeñaba su cargo en Washington en 1930-1931, donde llevaba una vida muy poco moral; o su afición por visitar estudios cinematográficos; o incluso el hecho de haber realizado campaña en contra de la CEDA a cuyos partidarios calificaba de «beatos».

La situación de los funcionarios diplomáticos declarados «disponibles" resultó no sei equitaiiva al ilevario i la práctica. En ifcuto, la pérdida de puestos en el escalafón obviamente beneficiaba a aquellos que se encontraban al finai del mismo y perjudicó a los que ocupaban los primeros puestos. Mediante la Ley de 24 de marzo de 1939 se trató de subsanar tal situación al especificar que los funcionarios declarados "disponibles" se verian postergados a los efectos del ascenso durante el plazo de efectividad de la sanción, plazo durante el cual deberia mencionarse "disponible por sanción» para distinguirsa de la situación normal de "disponible» prevista en las reglamentaciones ordinarias vigentes.

Fieron declarados «jubilados» aquellos diplomáticos que no presentaron su adhesión a la Junta de Defensa Nacional el 18 de julio de 1936 y permanecieron en sus puestos, siempre y cuando no hubiesen realizado servicios perjudiciales a la causa franquista. Los 18 diplomáticos declarados «jubilados» representan el 4,1 por 100 del total. La mayoría gozaba de buenas referencias en el Ministerio de Orden Público, tanto en el aspecto público como en el privado. El único cargo que se les imputó fue el haber dimitido fuera del plazo señalado por Franco.

Curiosamente cuatro de ellos habian sido cesados y separados del servicio por el Gebierno de la República con anterioridad al "pronunciado» del Tribunal Seleccionador. Tal es el caso de Julio López Oliván, Ministro

\footnotetext{
9 Véanse los informes del Ministerio del Interior sobre los diplomáticos declarados «disponibles". AMAE. Fondo Navasques. Depuración de funcionarios diplomáticos.
} 
Plenipotenciario de Segunda, que habia sido nombrado director de Política del Ministerio de Estado en 1931 por Alejandro Lerroux, pese a que el propio Oliván había declarado al ministro de Estado que era monárquico y que continuaría siéndolo. En junio de 1936 fue nombrado Embajador en Londres, pero Oliván que habia servido fielmente a la República, cuando se inició la guerra civil no pudo seguir como Embajador, ni tampoco unirse a las fuerzas rebeldes. El 30 de agosto fue cesado y separado del servicio por la República, y con posterioridad declarado «jubilado» por el Tribunal Seleccionador.

Teodomiro Aguilar y Salas había realizado una brillante carrera. Conocido por su rectitud moral y su apoliticismo, no exento de matiz derechista, fue expedientado con el advenimiento de la República en 1931. Sin embargo, absuelto de cualquier responsabilidad fue reintegrado en la Carrera. En abril de 1936 fue nombrado Embajador en Brasil, cargo que continuó desempeñando después del inicio de la guerra civil, por temor a que su familia sufriera represalias en España. Al formar Gobierno Largo Caballero dimitió de su cargo, siendo separado del Servicio el 9 de septiembre de 1936 por el Gobierno republicano. Sin embargo, las autoridades franquistas tuvieron en cuenta una carta que el Sr. Aguilar dirigió a Alvarez del Vayo poco antes de su dimisión, de cuyo contenido tuvo conocimiento el general Queipo de Llano, quien le criticó duramente. Con posteiroridad dicha carta fue publicada por el diario $A B C$ de Sevilla, hecho que motivó su detención al llegar a España. A pesar de estar considerado como persona de derechas y adicto al Movimiento recibió el «pronunciado» de «jubilado» el 19 de agosto de 1938.

José María Aguinaga y Barona tuvo una experiencia similar. Al estallar la guerra se encontraba ocupando el cargo de Embajador en Berna, pero a los pocos días fue enviado en comisión a Roma para que se hiciese cargo de la Embajada del Quirinal como consecuencia de la marcha forzada por sus subordinados del anterior Embajador, Manuel Aguirre de Cárcer. Cuando Aguinaga llegó a Roma el personal diplomático no le dejó tomar posesión de la Embajada. Refugiado en San Juan de Luz quiso entrar en la España de Franco, pero no se le permitió hacerlo. Al mismo tiempo el Gobierno de la República le separó del servicio el 9 de septiembre de 1936. En agosto de 1938 fue declarado «jubilado" por el Tribunal Seleccionador.

Del mismo modo Luis Quer y Boule, Consejero de la Embajada de Berlín fue separado de la Carrera por el Gobierno republicano el 28 de agosto de 1936 y dos años más tarde lo sería igualmente por el Tribunal Seleccionador, que le declaró «jubilado». 
El caso de los diplomáticos «jubilados" sentaba un precedente de difícil solución, al plantear el problema de aquellos funcionarios que sin poseer una ideología definida permanecieron en sus puestos como representantes del Estado español. Los sancionados podian alegar en su defensa el artículo $6^{\circ}$ de la Ley Orgánica de las Carreras Dipiomáticas y Consulares de 27 de abril de 1900, que preveia la adopción de sanciones por delitos cometidos dentro de la Carrera Diplomática, pero no por delitos ideológicos-políticos. Sin embargo, para el Tribunal Seleccionador los diplomáticos fueron considerados como "agentes políticos" puesto que su función en el extranjero debería reflejar el carácter político y representativo del régimen establecido en su pais, en este caso el del Gobierno de Fran$\mathrm{CO}^{10}$

Sesenta y dos diplomáticos fueron «separados» de la Carrera, lo que representa un 14,15 por 100 del total. Todos ellos poseian una ideología de izquierdas y apoyaron desde el 18 de julio de 1936 y a lo largo de toda la guerra al Gobierno de la República. En 25 casos éstos fueron los únicos cargos imputados aunque expresados de diferentes modos: Muy Rojo, Marxista, Muy Izquierdista o Muy Extremista ${ }^{11 .}$

En tres casos a la ideologia política se sumó el hecho de haber ostentado cargos públicos en el Gobierno republicano: Argimiro Maestro de León que fue subsecretario de la Presidencia del Consejo en el Gobierrio de Largo Caballero, Rafael Ureña, subsecretario del Ministerio de Estado en el Gobierno de Barcelona, y Adolfo Alvarez Buylla, secretario de la Presidencia con Martínez Barrios.

Dos diplomáticos fueron separados de la Carrera por haber pertenecido a partidos políticos integrados en el Frente Popular y uno por haber contribuido con 100 pts. para dicha formación en 1936. Un diplomático se vio acusado de firmar el Manifiesto a favor del Gobierno de Negrín y Prieto. Criatro diplomáticos fueron acusados por contrabando de armas y comestibles, y reclutamiento de voluntarios para las fuerzas republicanas. Dos de ellos además habian realizado funciones de espionaje, uno desde Tánger con el auxilio de marroquies e ingleses y otro desde el sur de Francia.

En tres casos no sólo se valoró el comportamiento político, sino también el moral. Así, un diplomático figura en los informes como amigo de Azaña y morfinómano; otro como el «prototipo de arribista sin escrúpulos»

\footnotetext{
10 Véanse los informes del Ministerio de Orden Público sobre los diplomáticos declarados «jubilados». AMAE. Fondo Navasques. Depuración de funcionarios diplomáticos.

11 Véanse los informes de los diplomáticos declarados «separados por el Tribunal Seleccionador». AMAE. Fondo Navasques. Depuración de funcionarios diplomáticos.
} 
y un tercero tenía su entrada prohibida en España por su dudosa conducta. Por último, los cinco diplomáticos citados anteriormente que fueron separados del Cuerpo por su pertenencia a Logias Masónicas entre otras consideraciones agravantes valoradas por el Tribunal Seleccionador.

De este grupo de diplomáticos «separados", cinco pertenecian a la promoción de 1933, única formada en el nuevo sistema impuesto por la República para la selección de los futuros diplomáticos ${ }^{12}$.

Al terminar el año 1938, 116 diplomáticos habian recibido un «pronunciado" aparejado de sanción. Precisamente porque tales "pronunciados" tuvieron carácter provisional, volvieron a plantearse nuevos recursos de alzada por parte de los diplomáticos interesados. Por ello, una vez más, se creó un nuevo Tribunal encargado de su revisión, que estuvo integrado por el presidente del Tribunal Seleccionador, los jefes de los Servicios Nacionales de Asuntos Administrativos, Política y Tratados del Ministerio de Asuntos Exteriores y el subsecretario del Ministerio, actuando como presidente el ministro de Asuntos Exteriores.

Próxima a terminar la guerra civil el Gobierno de Franco creyó llegado el momento de dictar una Ley de responsabilidades políticas para quienes habían entorpecido el triunfo del Movimiento Nacional. Dicha Ley de 9 de febrero de 1939 se vio reforzada por la Ley de Depuración de los funcionarios del Estado de 10 de febrero. Por lo que se refiere al personal del Ministerio de Asuntos Exteriores permanecieron en vigor las disposiciones dictadas con anterioridad para la depuración de los funcionarios diplomáticos. No obstante, el artículo $2^{\circ}$ de las disposiciones adicionales estipulaba que las sanciones impuestas con anterioridad a la promulgación de la Ley podrian ser revisadas con arreglo a las nuevas normas.

En efecto, desaparecidas las dificultades propias de la guerra al término de la misma, se procedió a la revisión de todos los expedientes del personal diplomático, al objeto de dar carácter definitivo a los "pronunciados" dictados por el Tribunal Seleccionador. Para llevar a cabo tal cometido se creó el 12 de abril de 1940 el Tribunal de Revisión de Expedientes de Depuración de Funcionarios del Ministerio de Asuntos Exteriores, formado por el Fiscal del Tribunal Supremo, un auditor de Guerra y dos diplomáticos, uno con categoria de embajador que actuaría como presidente y otro como secretario sin Voz ni voto. El cargo de Presidente recayó en Emilio Palacios de Fau, antiguo secretario general de Asuntos Exteriores durante la Dictadura del general Primo de Rivera. Actuó como secretario Carlos Rojas Moreno, conde de Torrellano.

\footnotetext{
12. Véanse los expedientes personales de Francisco Garcia Lorca, Juan March Lieutand, José Rovira Armengol, Salvador Téllez Molina, Luis Tobio Fernández. AMAE. Exp. 321-22723, $320-22719,312-22506,304-22292,315-22589$.
} 